chức năng của bàn tay cũng như chất lượng giấc ngủ của người bệnh sau mổ giải ép thân kinh giữa điều trị hội chứng ống cổ tay. Các khía cạnh của chất lượng giấc ngủ được cải thiện một cách toàn diện. Ngoài thang điểm Boston được khuyên dùng để đánh giá về mặt lâm sàng của mức độ nặng của triệu chứng và chức năng của bàn tay thì thang điểm PSQI nên được sử dụng như một tiêu chuẩn để đánh giá hiệu quả điêu trị hội chứng ống cổ tay.

\section{TÀI LIÊU THAM KHẢO}

1. Patel A., Culbertson M.D., Patel A. và cộng sứ. (2014). The negative effect of carpal tunnel syndrome on sleep quality. Sleep Disord, 2014, 962746.

2. Graham B., Regehr G., Naglie G. và cộng sự. (2006). Development and validation of diagnostic criteria for carpal tunnel syndrome. J Hand Surg, 31(6), 919-924.

3. Gangwisch J.E., Malaspina D., Boden-Albala B. và cộng sự. (2005). Inadequate sleep as a risk factor for obesity: analyses of the NHANES I.
Sleep, 28(10), 1289-1296.

4. Sampaio R.A.C., Sewo Sampaio P.Y., Yamada M. và cộng sứ. (2014). Self-reported quality of sleep is associated with bodily pain, vitality and cognitive impairment in Japanese older adults. Geriatr Gerontol Int, 14(3), 628-635.

5. Rubin G., Orbach H., Rinott M. và cộng sự. (2020). Relationship between electrodiagnostic findings and sleep disturbance in carpal tunnel syndrome: A controlled objective and subjective study. J Int Med Res, 48(2), 030006051986267.

6. Karatas G., Kutluk O., Akyuz M. và cộng sự. (2020). The effects of carpal tunnel syndrome on sleep quality. Ann Med Res, 27(1), 381.

7. Trung D.T., Ngoc T.M., Gia D.H. và cộng sự. (2019). Endoscopic carpal tunnel release surgery: a case study in Vietnam. $J$ Orthop Surg, 14(1), 149.

8. Tulipan J.E., Kim N., Abboudi J. và cộng sự. (2017). Prospective Evaluation of Sleep Improvement Following Carpal Tunnel Release Surgery. J Hand Surg, 42(5), 390.e1-390.e6.

9. Okkesim C.E., Serbest S., Tiftikçi U. và công sứ. (2019). Prospective evaluation of preoperative and postoperative sleep quality in carpal tunnel release. J Hand Surg Eur Vol, 44(3), 278-282.

\title{
LIÊN QUAN GIỮA SÓNG TIỀN TÂM THU THẤT TRÁI VỚI CHỨC NĂNG TÂM TRƯƠNG THẤT TRÁI TRÊN SIÊU ÂM TIM Ở BÊ̂NH NHÂN ĐÁI THÁO ĐƯỜ'NG TYP 2
}

\section{TÓM TẮT}

Mục tiêu: Tìm hiểu mối liên quan giữa sóng tiền tâm thu (TTT) thất trái với một số thông số chức năng tâm trương (CNTTr) thất trái trên siêu âm tim ở bệnh nhân (BN) đái tháo đường (ĐTĐ) typ 2. Đối tượng và phương pháp: Nghiên cứu mô tả, cắt ngang trên 60 BN ĐTÐ typ 2 và 30 người nhóm chứng tại khoa Nội tiết và Viện Tim mạch Bệnh viện Bạch Mai từ tháng 8/2020 đến tháng 8/2021. Các thông số nghiên cứu (NC) trên siêu âm tim: vận tốc và thời gian sóng TTT đo tại đường ra thất trái, kích thước và chức năng tâm trương thất trái, chỉ số Tei thất trái. Kết quả: Tỳ lệ sóng TTT thất trái là 90\% ở nhóm ĐTĐ, 93,3\% ở nhóm chứng ( $p: 0,600)$. Có $35 \%(21 B N)$ trong nhóm ĐTĐ có rối loạn CNTTr thất trái, trong đó $81 \%$ (17BN) là rối loạn CNTTr độ I, 19\% (4BN) là rối loạn CNTTr độ II. Có $6,7 \%$ (2BN) trong nhóm chứng có rôi loạn CNTTr thất trái (độ I). Đường kính thất trái tâm trương và thể tích thất trái tâm trương ở nhóm không có sóng TTT lớn hơn so với nhóm có sóng TTT

\footnotetext{
${ }^{1}$ Trường Đại học y Hà Nội

${ }^{2}$ Viện tim mạch Việt Nam, Bệnh viện Bạch Mai

Chịu trách nhiệm chính: Lê Thị Mai Sao

Email: lemaisaomlvp@gmail.com

Ngày nhận bài: 27.7.2021

Ngày phản biện khoa học: 30.9.2021

Ngày duyệt băi: 5.10 .2021
}

Lê Thị Mai Sao', Phạm Thị Hồng Thi²

$(p<0,05)$. Vận tốc sóng tiền tâm thu ở đường ra thất trái tương quan đồng biến với vận tốc sóng $A$ qua van 2 lá (rho $=0,413, p<0,001$ ), tương quan nghịch biến với tî lệ $E / A$ (rho $=-0,244, p=0,027$ ), tương quan đồng biến với chỉ số Tei thất trái (rho $=0,345$, $\mathrm{p}<0,005$ ).

Tư khóa: sóng tiền tâm thu thất trái; đái tháo đường typ 2; chức năng tâm trương thất trái; chỉ số Tei.

\section{SUMMARY \\ ASSOCIATION BETWEEN LEFT \\ VENTRICULAR'S PRESYSTOLIC WAVE AND LEFT VENTRICULAR DIASTOLIC FUNCTION \\ ON ECHOCARDIOGRAPHY IN TYPE 2 DIABETES MELLITUS PATIENTS}

Aims: Assess the association between left ventricular's presystolic wave and some of left ventricular diastolic function's values on echocardiography in types 2 diabetes mellitus patients. Patients and methods: we performed a descriptive cross - sectional study included 90 patients: 60 type 2 diabetes mellitus patients and 30 healthy subjects in endocrinology department - Bach Mai hospital and Vietnam National Heart institue. The researched values included: velocity and times of the presystolic wave mesured in LVOT, size and diastolic function of the left ventricular, Tei index. Results:The ratio of presystolic wave in LVOT is $90 \%$ in type 2 Diabetes 
Mellitus group and is $93,3 \%$ in healthy subjects' group. $35 \%$ of (21 patients) in type 2 Diabetes Mellitus group have left ventricular diastolic dysfunction, $81 \%(17$ patients) of those are left ventricular diastolic dysfunction grade $1,19 \%$ (4 patients) of those are at grade 2 . There are $6,7 \%$ (2 patients) in healthy subjects' group have left ventricular diastolic dysfunction (grade 1). Diastolic diameter and diastolic volume of the left ventricular in the group absent of presystolic wave is higher than the group with presystolic waves $(p<0,05)$. Velocity of presystolic wave in LVOT has a positive colleration with A wave's velocity mesured in mitral valves level (rho $=0,41, p$ $<0,01$ ), a negative colleration with $\mathrm{E} / \mathrm{A}$ ratio ( $\mathrm{rho}=0$, $0,244, p=0,027)$ and a positive colleration with Tei index of the left ventricular (rho $=0,345, p<0,05$ ).

Keywords: left ventricular's presystolic wave; type 2 Diabetes mellitus; Left ventricular diastolic function; Tei index.

\section{I. ĐĂT VẤN ĐỀ}

Đái tháo đường là bệnh nội tiết và rối loạn chuyển hóa phổ biến nhất ở nhiều nước, gây ra nhiều biến chứng về tim mạch ${ }^{1}$. Suy tim ở bệnh nhân ĐTĐ trong đó suy CNTTr thường xuất hiện trước, thậm chí ngay cả giai đoạn bệnh chưa có triệu chứng lâm sàng trong khi chức năng tâm thu vẫn còn bình thường ${ }^{2}$. Do đó, việc chẩn đoán sớm các rối loạn ẩn dấu này, sẽ giúp các nhà lâm sàng có phương án chiến lược điều trị tốt nhất cho mổi bệnh nhân. Sóng tiền tâm thu là một sóng thường được tìm thấy khi đánh giá tại đường ra thất trái bằng siêu âm doppler. Sự xuất hiện của sóng TTT có liên quan đến sự kém chun giãn và độ cứng của tâm thất trái, và sóng này có thể xuất hiện từ giai đoạn rối loạn chức năng tim ẩn dấu ${ }^{3}$. Đây là một chỉ dấu tưởng đối dễ thu thập trong quá trình thực hành siêu âm, góp phần vào đánh giá các rối loạn chức năng tim ở trên các bệnh nhân tim mạch, đặc biệt với các bệnh lý tim mạch liên quan đển ĐTĐ. Tuy vậy, dấu hiệu này hiện tại còn chưa được ứng dụng vào trong thực hành siêu âm tại Việt Nam, do đó, chúng tôi tiến hành NC này nhằm tìm hiểu mối liên quan giữa sóng $T T$ thất trái với CNTTr thất trái trên siêu âm tim ở bệnh nhân ĐTĐ typ 2.

\section{II. ĐỐI TƯỢNG VÀ PHƯƠ'NG PHÁP NGHIÊN CỨU}

Đối tượng nghiên cứu: $\mathrm{NC}$ được tiến hành trên 60 BN ĐTĐ typ 2 (nhóm bệnh) và 30 người khỏe mạnh (nhóm chứng) điều trị tại khoa Nội tiết và Viện tim mạch Bệnh viện Bạch Mai từ tháng 8/2020 đến tháng 8/2021.

- Nhóm bệnh: Chẩn đoán ĐTĐ typ 2 theo các tiêu chuẩn của Hiệp hội đái tháo đường Hoa Kỳ (ADA) năm 20194. BN đồng ý tham gia nghiên cứu. Loại khỏi nhóm NC những trường hợp có các bệnh lý như bệnh cơ tim phì đại, bệnh mạch vành mạn tính, nhồi máu cơ tim, bệnh mạch máu ngoại biên, bệnh lý van tim từ vừa tới nặng, bệnh tim bẩm sinh, rung nhĩ, suy tim EF giảm, phụ nữ có thai, bệnh lý cấp cứu về bệnh nộingoại khoa.

- Nhóm chứng: Không có bệnh lý nội - ngoại khoa và đồng ý tham gia nghiên cứu

Phương pháp nghiên cứu: Nghiên cứu mô tả, cắt ngang. Tất cả $B N$ nghiên cứu được hỏi tiền sử, khám lâm sàng và chỉ định làm xét nghiệm cần thiết để xác định ĐTĐ typ 2. BN được làm siêu âm tim trên cùng hệ thống máy siêu âm tim Vivid E95 (GE) với đâuu dò ma trận 2D M5Sc-D, cho phép tính toán các thông số đánh giá chức năng tim và các thông số Doppler một cách tự động. Tất cả các đối tượng nghiên cứu (nhóm bệnh, nhóm chứng) đều được thực hiện siêu âm bởi cùng một bác sĩ chuyên về siểu âm tim.

Các thông số đánh giá: Vận tốc và thời gian sóng TTा thất trái, đường kính và thể tích thất trái cuối tâm trương, chỉ số thể tích nhĩ trái (LAVI), vận tốc sóng $E$, sóng $A$, tỷ lệ $E / A$, vận tốc sóng $\mathrm{e}^{\prime}$ vách, $\mathrm{e}^{\prime}$ thành bên, vận tốc dòng hở ba lá, chỉ số chức năng toàn bộ thất trái (Tei thất trái). Đo chỉ số Tei thất trái thông qua thời gian co đồng thể tích (IVCT) và thời gian giãn đồng thể tích (IVRT), thời gian tống máu thất trái( ET). Các số liệu được thu thập theo mẫu bệnh án nghiên cứu và xử lý số liệu bằng phần mềm SPSS 16.0.

\section{KẾT QUẢ NGHIÊN CỨU}

Đặc điểm chung của nhóm nghiên cứu. Trong thời gian từ tháng $8 / 2020$ đến tháng $8 / 2021$ chúng tôi đã NC trên 60 BN ĐTÐ typ 2 so với 30 đối tượng ở nhóm chứng, thấy không có sự khác biệt đáng kể về tỷ lệ nam/ nữ (41/19 so với $18 / 12, p=0.43)$ và tuổi trung bình $(54,1 \pm$ 11,2 so với $50,8 \pm 10,4, p=0.189$ ). Trong nhóm $\mathrm{BN}$ ĐTÐ có thời gian mắc bệnh trung bình là 6,1 $\pm 7,1$ năm, số lượng $B N$ ĐTंĐ typ 2 mới mắc là 23 BN (25,6\%).

Liên quan giữa sóng $\mathrm{TTT}$ thất trái và CNTTr thất trái ở bệnh nhân ĐTÐ typ2. Nghiên cứu trên 90 đối tượng bao gồm 60 BN ĐTÐ và 30 người nhóm chứng, chúng tôi ghi được kết quả xuất hiện sóng TाT thất trái ở nhóm ĐTÐ là $90 \%$ và $93,3 \%$ ở nhóm chứng. Tuy nhiên sự khác biệt này chưa có ý nghĩa thống kê (p: 0,600$)$. Tỷ lệ RLCNTTr thất trái là $35 \%$ (21BN) ở nhóm ĐTंĐ trong đó $81 \%$ (17BN) là rối loan CNTTr đô I, 19\% (4BN) là rối loan CNTTr độ II. Có $6,7 \%$ (2BN) trong nhóm chứng có rôi loạn CNTTr thất trái (độ I). 
Bảng 1. Sự khác biệt về kích thước tâm trương thất trái trên siêu âm tim giữa 2 nhóm có và không có sóng TiTT ở nhóm bệnh nhân đái tháo đường

\begin{tabular}{|c|c|c|c|}
\hline \multirow{2}{*}{ Thông số SAT } & Kóng TTT thất trái STT $(\mathbf{n = 5 4})$ & Không STTT $(\mathbf{n = 6})$ & \\
\cline { 2 - 4 } & TB \pm SD & TB \pm SD & p \\
\hline ĐK thất trái tâm trương $(\mathrm{mm})$ & $40.7 \pm 4.7$ & $45.6 \pm 4.7$ & $\mathbf{0 . 0 5 0}$ \\
\hline BD VLT tâm trương $(\mathrm{mm})$ & $10 \pm 10.8$ & $8 \pm 0.9$ & 0.186 \\
\hline BD TSTT tâm trương $(\mathrm{mm})$ & $9.7 \pm 10.8$ & $7.7 \pm 0.8$ & 0.177 \\
\hline TT thất trái tâm trương $(\mathrm{ml})$ & $69.7 \pm 24.2$ & $97.5 \pm 24$ & $\mathbf{0 . 0 3 6}$ \\
\hline
\end{tabular}

Đường kính thất trái tâm trương (45.6 \pm 4.7$)$, và thể tích thất trái tâm trương $(97.5 \pm 24)$ ở nhóm không có STTT lớn hơn so với nhóm có STTT $(40.7 \pm 4.7)$ và $(69.7 \pm 24.2)$, p<0,05.

Bảng 2. Sự khác biệt về các thông số chức năng tâm trương thất trái giứa 2 nhóm có và không có sóng TTT thất trái ở nhóm bệnh nhân đái tháo đường.

\begin{tabular}{|c|c|c|c|}
\hline \multirow{2}{*}{ Thông số SAT } & Có STTT ( $n=54)$ & Không STT $(n=6)$ & \\
\hline & TB \pm SD & TB \pm SD & $\mathbf{p}$ \\
\hline $\mathrm{e}^{\prime}$ vách $(\mathrm{cm} / \mathrm{s})$ & $7.3 \pm 1.6$ & $7.4 \pm 1.4$ & 0.851 \\
\hline $\mathrm{e}^{\prime}$ trung bình $(\mathrm{cm} / \mathrm{s})$ & $9.9 \pm 2.5$ & $10.5 \pm 0.5$ & 0.150 \\
\hline Sóng E (cm/s) & $64.5 \pm 17.9$ & $58.8 \pm 11.1$ & 0.298 \\
\hline Sóng $A(\mathrm{~cm} / \mathrm{s})$ & $67.9 \pm 16.7$ & $70.3 \pm 25.2$ & 0.827 \\
\hline Chỉ số E/A & $1 \pm 0.3$ & $0.9 \pm 0.3$ & 0.588 \\
\hline Chỉ số E/e' & $6.8 \pm 1.9$ & $5.7 \pm 1.3$ & 0.102 \\
\hline Chỉ số thể tích nhĩ trái (ml) & $25.6 \pm 5.6$ & $23.8 \pm 6.3$ & 0.525 \\
\hline Vân tốc dòng hở qua van 3 lá (m/s) & $2.1 \pm 2.9$ & $2.2 \pm 0.2$ & 0.809 \\
\hline
\end{tabular}

Các thông số chức năng tâm trương thất trái giữa 2 nhóm có và không có sóng $\Pi \pi$ thất trái không có sự khác biệt có ý nghĩa thông kê.

Bảng 3. Tương quan giữa vận tốc, thời gian sóng TTT thất trái với kích thước tâm trương thất trái

\begin{tabular}{|c|c|c|c|c|}
\hline \multirow{2}{*}{ Shóng TTT thất trái } & \multicolumn{2}{|c|}{ Vận tốc STTT (n=82) } & \multicolumn{2}{c|}{ Thời gian STT (n=82) } \\
\cline { 3 - 5 } Thống SAT & rho & $\mathbf{p}$ & rho & $\mathbf{p}$ \\
\hline ĐK thất trái tâm trương $(\mathrm{mm})$ & -0.101 & 0.368 & 0.106 & 0.341 \\
\hline BD VLT tâm trương $(\mathrm{mm})$ & -0.081 & 0.470 & 0.252 & $\mathbf{0 . 0 2 2}$ \\
\hline BD TSTT tâm trương $(\mathrm{mm})$ & -0.114 & 0.307 & 0.241 & $\mathbf{0 . 0 2 9}$ \\
\hline TT thất trái tâm trương $(\mathrm{ml})$ & -0.088 & 0.433 & 0.124 & 0.268 \\
\hline
\end{tabular}

Có mối tương quan giữa thời gian sóng TTा với bề dày VLT tâm trương ( $r: 0.252, \mathrm{p}: 0.022)$ và bề dày thành sau thất trái tâm trương ( $r: 0.241, p: 0,029)$. Tuy nhiên mối tương quan này yếu.

Bảng 4. Tương quan giữa vận tốc, thời gian STTT thất trái với chức năng tâm trương thất trái

\begin{tabular}{|c|c|c|c|c|}
\hline \multirow{2}{*}{ Sóng TTT thất trái } & \multicolumn{2}{|c|}{ Vận tốc STT (n=82) } & \multicolumn{2}{c|}{ Thời gian STT (n=82) } \\
\cline { 2 - 5 } & rho & $\mathbf{p}$ & rho & $\mathbf{p}$ \\
\hline Chỉ số Tei thất trái & $\mathbf{0 . 3 4 5}$ & $\mathbf{0 . 0 0 2}$ & $\mathbf{0 . 0 7 7}$ & 0.493 \\
\hline $\mathrm{e}^{\prime}$ vách $(\mathrm{cm} / \mathrm{s})$ & -0.069 & 0.538 & -0.147 & 0.186 \\
\hline $\mathrm{e}^{\prime}$ trung bình $(\mathrm{cm} / \mathrm{s})$ & -0.179 & 0.107 & -0.116 & 0.299 \\
\hline Sóng $\mathrm{E}(\mathrm{cm} / \mathrm{s})$ & 0.103 & 0.357 & 0.012 & 0.912 \\
\hline Sóng A (cm/s) & $\mathbf{0 . 4 1 3}$ & $\mathbf{0 . 0 0 0}$ & 0.141 & 0.208 \\
\hline Chỉ số E/A & $\mathbf{- 0 . 2 4 4}$ & $\mathbf{0 . 0 2 7}$ & -0.106 & 0.344 \\
\hline Chỉ số E/e' & 0.198 & 0.075 & 0.086 & 0.442 \\
\hline Chỉ số thế tích nhĩ trái $(\mathrm{ml})$ & 0.077 & 0.494 & 0.062 & 0.580 \\
\hline Vận tốc dòng hớ qua van 3 lá $(\mathrm{m} / \mathrm{s})$ & -0.074 & 0.509 & 0.323 & 0.003 \\
\hline
\end{tabular}

Có mối tương quan thuận giữa vận tốc sóng TTT thất trái và chỉ số Tei thất trái (rho $=0.345$, $\mathrm{p}=0.002$ ). Có mối tương quan đồng biến giữa vận tốc sóng TTT thất trái và vận tốc sóng $A$ qua van 2 lá (rho $=0,413, p<0,001$ ). Có mối tương quan nghịch biến giữa vận tốc STTT thất trái và chỉ số $E / A$ (rho $=-0.244, p=0.027$ ). Không có mối tương quan giữa thời gian sóng TTT thất trái với các thông số CNTTr thất trái. 


\section{BÀN LUÂN}

Theo kết quả NC của chúng tôi, sóng TाT thất trái xuất hiện ở 91,1\% nhóm chung, 90\% nhóm ĐTĐ và 93,3 \% ở nhóm chứng ( $p: 0,600)$. Theo NC của Kul ${ }^{3}$ và cs (2019) trên 120 BN ĐTĐ typ 2, thì tỉ lệ sóng TTT thất trái ở BN ĐTĐ là $69 \%$. Cũng trong NC của chúng tôi, tỉ lệ rối loạn CNTTr thất trái chiếm 35\% (21BN) ở nhóm ĐTĐ, trong đó $81 \%$ (17BN) là rối loạn CNTTr độ I, $19 \%$ (4BN) là rối loạn CNTTr độ II, và có $6,7 \%$ (2BN) trong nhóm chứng có rối loạn CNTTr thất trái (độ I). Theo nghiên cứu của Nguyễn Thu Hiên ${ }^{5}$ và cS. năm 2021, tỉ lệ rối loạn CNTTr thất trái ở trên BN ĐTĐ chiếm $51,7 \%$, trong đó giai đoạn I: 41\%, giai đoạn II: 45,9\%, giai đoạn III: $13,1 \%$. Các kết quả này cao hơn so với Nic của chúng tôi, do đối tượng NC của chúng tôi có tuổi và thời gian mắc bệnh ĐTĐ thấp hơn so với tác giả.

Trong NC của chúng tôi cho thây đường kính thất trái tâm trương (45.6 \pm 4.7$)$, và thể tích thất trái tâm trương (97.5 \pm 24) ở nhóm không có sóng TTT lớn hơn so với nhóm có sóng TTT (40.7 \pm 4.7) và $(69.7 \pm 24.2), p<0,05$. (Bảng 1). Kết quả này cũng tương tự như nghiên cứu của Uzun 6 và cs (năm 2020). Ngoài ra chúng tôi cũng nhận thấy rằng vận tốc sóng TTT thất trái có tương quan đồng biến với vận tốc sóng $A$ qua van 2 lá (rho $=0,413, p<0,001$ ), và tương quan nghịch biến với tỉ lệ $E / A$ (rho $=-0,244, p<$ 0,05). (bảng 4). NC của Akyuz ${ }^{7}$ và cS (2016) cũng cho thấy những mối tương quan này.

Sóng TTT thất trái có nguôn gốc từ các dòng chảy xoáy do dòng máu khi đổ từ van 2 lá vào thất trái tạo ra, do đó những tính chất của buồng thất trái sẽ ảnh hưởng đến vector dòng chảy này. Sự gia tăng độ cứng của thất trái sẽ làm gia tăng áp lực thất trái vào thời kỳ nhĩ trái thu, và chính yếu tố này làmm tăng động năng của dòng xoáy, do đó sẽ dẫn đến sự tăng vận tốc của sóng TTT. Đến những giai đoạn sau, khi thất trái trở nên giãn ra, lúc này, do sự phân tán của momen động năng của dòng chảy qua van 2 lá, sẽ khiến cho momen lực trở nên rất yếu và các sóng này sẽ trở nên giảm vận tốc. Như vậy, có thể thấy, vận tốc sóng TTT thất trái cũng như sự hiện diện của nó sẽ có liên quan đến giai đoạn suy CNTTr thất trái. Một cơ chế khác của sóng TTT liên quan đến thời gian truyền qua van 2 lá, mà đặc biệt trong đó là dòng chảy do co bóp nhĩ trái ở giai đoạn tiên nhĩ thu. Điêu này cũng giải thích vì sao vận tốc sóng TTT có mối tương quan đồng biến sóng A qua van 2 lá.

NC của chúng tôi cũng thây rằng vận tốc sóng TTा có tương quan đồng biến với chỉ số Tei thất trái (rho $=0,345, p<0,05)$. Theo kết quả NC của Kul ${ }^{3}$ và cs (2019), nhóm bệnh nhân có sóng TTT có chỉ số Tei thất trái cao hơn ở nhóm không có sóng TTT. Chỉ số Tei là công cụ dễ thực hiện không xâm lấn phản ánh chức năng tâm thu và tâm trương. Nó sử dụng để tiên đoán tổn thương thất trái và tiến triển của suy tim một thời gian lâu trước khi có biểu hiên lâm sàng rõ rệt. Do đó chỉ số Tei được sử dụng để phát hiện suy chức năng thất trái dưới cận lâm sàng. Trong bệnh ĐTĐ, nhiêu cơ chế gấy tổn thương tế bào cơ tim, dấn tới tăng độ cứng và giảm độ chun giãn của thành thất trái, do đó cơ tim cân một khoảng thư giãn dài hơn để đảm bảo đây máu thất và duy trì áp lực cuối tâm trương (tăng IVRT), đồng thời co bóp của tế bào cơ tim cũng bị ảnh hưởng không duy trì được một áp lực tống máu đủ dài (ET giảm), vì thế chỉ số Tei tăng lên. Đồng thời sự tăng độ cứng và giảm độ chun giãn của thành thất cũng làm vận tốc sóng TTT tăng lên.

Tóm lại, tổn thương sự co giãn của tâm thất trái và gia tăng độ cứng có thể ảnh hưởng đến sự xuất hiện sóng TTT ở bệnh nhân ĐTĐ và sóng TTT có thể xuất hiện ở bệnh nhân ĐTĐ có suy CNTTr ẩn dấu.

\section{KẾT LUẬN}

- Tỷ lệ sóng TTT thất trái là $90 \%$ ở nhóm ĐTĐ, 93,3\% ở nhóm chứng nhưng sự khác biệt chưa có ý nghĩa thống kê ( $p>0,05)$.

- Vận tốc sóng TTT thất trái có tương quan đồng biến với vận tốc sóng A qua van 2 lá (rho = $0,413, p<0,001)$, và tương quan nghịch biến với tỉ lệ $E / A$ (rho = -0,244, p < 0,05). Vận tốc sóng TTTं có tương quan đông biến với chỉ số Tei thất trái (rho $=0,345, \mathrm{p}<0,05$ ).

- Tỷ lệ suy CNTTr thất trái ở bệnh nhân ĐTĐ cao hơn nhóm chứng $(p<0,05)$. 35\% (21BN) trong nhóm ĐTĐ có rối loạn CNTTr thất trái, trong đó $81 \%$ (17BN) là rối loạn CNTTr độ I, 19\% (4BN) là rối loạn CNTTr độ II.

\section{TÀI LIÊU THAM KHẢO}

1. Trân Hữu Dàng, Thái Hồng Quang, \& Nguyễn Hải Thủy và CS. Bệnh lý tim mach và các khuyến cáo điều trị các nguy cơ tim mạch ở bệnh nhân đái tháo đường. Hội Nội Tiết Và Đái Tháo Đường Việt Nam (2018).

2. Patil, V. C., Patil, H. V., Shah, K. B., Vasani, J. D. \& Shetty, P. Diastolic dysfunction in asymptomatic type 2 diabetes mellitus with normal systolic function. J. Cardiovasc. Dis. Res.2, 213222 (2011).

3. Kul, S. et al. Presystolic Wave is Associated with Subclinical Left Ventricular Dysfunction Assessed by Myocardial Performance Index in Type 2 
Diabetes Mellitus. Arq. Bras. Cardiol. (2019) doi:10.5935/abc.20190134.

4. American Diabetes Association. Classification and Diagnosis of Diabetes ADA 2019. Diabetes Care42, S13-S28 (2019).

5. Nguyễn T. H. \& Phạm T. T. Khảo sát tỷ lệ rối loan chức năng tâm trương thất trái ở bệnh ninhân đái tháo đướng típ 2. Vietnam J. Diabetes Endocrinol. 43-48 (2021) doi:10.47122/ vjde.2020.44.6.

6. Uzun, G., Kirci, D., Korkmaz, L., z, A. A. \& Sayin, M. What is Good for Hypertensive Patients: Presence or Absence of Presystolic Wave. (2020) doi:10.22541/au.160157505.56187587.

7. Akyüz, A. R. et al. The relationship between presystolic wave and subclinical left ventricular dysfunction in asymptomatic hypertensive patients. Blood Press. Monit. 21, 277-281 (2016).

\section{ĐÁNH GIÁ KẾT QUẢ PHỤC HỒI CHỨC NĂNG KHỚP GỐI SAU PHẪU THUÂ̂T NộI SOI GÕ̃ DÍNH}

\section{TÓM TẮT}

Cứng khớp gối là một biến chứng phức tạp tiềm ẩn sau mỗi phẫu thuât hoặc chấn thương khớp gối. Có nhiều phương pháp điêu trị biến chứng này trong đó phẫu thuâat nôi soi gỡ dính đang ngày càng được ưa chuộng. Nhiều nghiên cứu trên thể giới và Việt $\mathrm{Nam}$ đều chỉ ra rằng bệnh nhân cần môt chương trình phục hồi chức năng toàn diện sau phầu thuật nội soi gõ dính khớp gối. Vì vậy chúng tôi tiến hành nghiên cứu nhằm mục tiêu: (1) Đánh giá kêt quả phục hồi chức năng vận động khớp gối sau phẫu thuật nội soi gõ dính. (2) Tìm hiểu một số yếu tố ảnh hưởng tới khả năng phục hồi chức nẳng vận động khớp gối sau phẫu thuật nội soi gõ̃ dính khớp gối. Đối tượng: 25 bệnh nhân đđược chẩn đoán cứng khớp gối sau chấn thương đã phẩu thuật nội soi gõ dính tại Bệnh viện Hữu nghị Việt Đức từ tháng 9/2020 đến tháng 7/2021. Phương pháp: tiến cứu, đánh giá trước và sau can thiệp, không có nhóm chứng. Kết quả: Tai nạn giao thông là nguyên nhân hàng đầu gây chấn thương ban đâu (76\%). Gãy xương khác ngoài xương đùi và đứt dây chằng là 2 tổn thương thường găp nhất, $52 \%$ bệnh nhân trong 2 nhóm trên có tốn thương phối hợp. Nhóm BN cứng gối sau phẫu thuật (23 BN) nhiêuu hơn nhóm điều trị bảo tồn (2 BN), tổn thương nội khớp (gãy xương nội khớp $40 \%$, tổn thương phần mềm $60 \%$ ) nhiêu hởn tổn thương ngoại khớp (16\%). Tầm vận động trung bình sau tập phục hồi chức năng 8 tuần $(118,92 \pm 14,06$ độ) tăng 56 độ so với trước mổ $(62,2 \pm 26,38$ độ). Tî lệ bệnh nhân đạt kết quả phuc hồi chức năng rất tốt tăng rõ rệt từ $8 \%$ (trước phẩu thuật) lên $92 \%$ và không có bệnh nhân loại trung bình và kém sau 8 tuần điêu trị. Nhóm tổn thương ngoai khớp có điểm HSS trung bình sau điều trị cao nhẩt $(95,5 \pm 3,11)$. Nhóm gãy xương khác có điểm HSS trung bình sau điêu trị cao nhất $(93,62 \pm 4,72) .52 \%$ bệnh nhân được phẫu thuật $g$ õ dính sau chấn thương 3-6 tháng và không có sự khác biệt có ý nghĩa thống

*Trường Đại học Y Hà Nôi

Chịu trách nhiệm chính: Lương Thu Hằng

Email: luongthuhanghb1210@gmail.com

Ngày nhận bài: 2.8.2021

Ngày phản biên khoa học: 1.10.2021

Ngày duyệt bài: 7.10.2021

\section{Lương Thu Hằng*, Phạm Văn Minh*}

kê trong kết quả điều trị giữa các nhóm thời gian phẫu thuật gỡ dính. Kết luận: Phẫu thuật nội soi gỡ dính khớp gối kết hợp với một chương trình phục hồi chức năng toàn diện đem lại hiệu quả lớn trong gia tăng tầm vận động và cải thiện chức năng khớp gối. Một số yếu tổ có ảnhh hưởng đển kết quả phục hồi chức năng khớp gối là chấn thương ban đâu gây tổn thương nội khớp hay ngoại khớp, chấn thương gây xơ dính nộ̣i khớp hay ngoại khớp, điêuu trị chấn thương bằng phẫu thuật hay bảo tồn, thời gian phẫu thuật nội soi là yếu tố cần nghiên cứu thêm.

Từ khóa: Cứng khớp gối sau chấn thương, sau phẫu thuật nội soi gõ dính

\section{SUMMARY}

\section{EVALUATE THE RESULTS OF}

\section{REHABILITATION OF KNEE JOINT AFTER}

\section{ARTHROSCOPIC ARTHROFIBROSIS}

Knee stiffness is a potentially complex complication after any surgery or injury to the knee joint. There are many treatment methods for this complication, of which arthroscopic arthrofibrosis is becoming increasingly popular. Many studies in the world and in Vietnam have shown that patients need a comprehensive rehabilitation program after arthroscopic arthrofibrosis. Therefore, we conducted a study with the following objectives: (1) Evaluate the results of rehabilitation of knee joint mobility after arthroscopic arthrofibrosis. (2) Learn some factors affecting the ability to restore knee mobility after arthroscopic arthrofibrosis knee. Subjects: 25 patients diagnosed with post-traumatic knee stiffness underwent arthroscopic arthrofibrosis at Viet Duc University Hospital from 9/2020 to 7/2021. Methods: prospective, evaluated before and after the intervention, without a control group. Results: Traffic accidents are the leading cause of primary injury $(76 \%)$. Fractures other than the femur and ligament tears are the two most common injuries, $52 \%$ of patients in the two groups above have combined lesions. The group of patients with knee stiffness after surgery (23 patients) more than the conservative treatment group (2 patients), intra-articular damage (intra-articular fracture $40 \%$, soft tissue damage 60\%) more than extra-articular damage (16\%). The average range of motion after 8 weeks of rehabilitation 